\title{
Management control design in long-term buyer-supplier relationships: Unpacking the learning process
}

\author{
Kristof Stouthuysen $^{\mathrm{a}, \mathrm{d}, *}$, Alexandra Van Den Abbeele ${ }^{\mathrm{b}}$, Jeltje van der Meer-Kooistra ${ }^{\mathrm{c}}$, \\ Filip Roodhooft $\mathrm{d}^{\mathrm{d}}$ \\ ${ }^{a}$ Vlerick Business School \& KU Leuven, Vlamingenstraat 83, 3000, Leuven, Belgium \\ ${ }^{\mathrm{b}} \mathrm{KU}$, Leuven, Belgium \\ ${ }^{\mathrm{c}}$ University of Groningen, the Netherlands \\ ${ }^{\mathrm{d}}$ Vlerick Business School \& KU, Leuven, Belgium
}

\section{A R T I C L E I N F O}

\section{Keywords:}

Management control design

Learning processes

Boundary spanners

Multi-level process analysis

Long-term buyer-supplier relationships

\begin{abstract}
A B S T R A C T
Management control (MC) design is crucial to the success of buyer-supplier relationships, yet we know little about how a buying company designs the management controls (MCs) of such relationships over time. In this paper, we use data collected in a six-year field study on the design of the MCs of a new facilities management (FM) outsourcing relationship. We find that boundary spanners learn to control in multiple ways, including trial and error, advice from third parties, experimentation, cross-level learning (i.e., corporate boundary spanners learning from operating boundary spanners), and advice from the partner. Moreover, the role of boundary spanners influences their focus of learning attention, with corporate boundary spanners focusing more on strategic aspects of the relationship (such as reducing appropriation concerns), and operating boundary spanners focusing more on FM activities and the coordination problems related to these activities. The lessons learned by both types of boundary spanners lead to the design of different types of control.
\end{abstract}

\section{Introduction}

In this article we study how a buying company learns to design the management controls (MCs) adopted to manage its supplier over time. A major stream of the management accounting literature draws primarily on transaction cost economics (TCE) to assume that parties are able to foresee threats and develop optimal management control (MC) designs at the outset of inter-organizational relationships (e.g., Anderson and Dekker, 2005; Phua et al., 2011; Dekker et al., 2013; Van der Meer-Kooistra and Vosselman, 2000). Other management scholars question these assumptions (Ariño et al., 2014; Mayer and Argyres, 2004), focusing on learning as a factor that explains MC design. In particular, several studies find support for trial-and-error learning (e.g., Dekker and Van den Abbeele, 2010; Mayer and Argyres, 2004; Ryall and Sampson, 2009; Vanneste and Puranam, 2010), in which MCs evolve in response to buyer-supplier interactions over time.

But trial-and-error learning is not likely to be the only source of learning in the development of effective MCs over the life of a buyer- supplier relationship. Organizations may also learn from the advice of third parties or from experimentation (Bingham and Davis, 2012). In addition, while prior studies examine learning at the corporate level (e.g., Mayer and Argyres, 2004; Vanneste and Puranam, 2010), decision makers at other management levels can learn how to control the buyersupplier relationships in which they are involved. Another shortcoming of existing studies is that they focus mainly on the number of contractual clauses as an outcome of learning efforts, rather than the development of MCs in the course of a relationship.

In this article we seek to move toward a more nuanced account of how parties learn to control their buyer-supplier relationships. To do so, we study how decision makers, or "boundary spanners", at the corporate and operating management levels in a buying company, learn to control a buyer-supplier relationship over time. ${ }^{1}$ Specifically, we examine a new facilities-management outsourcing relationship over a period of six years. This outsourcing relationship involved a large Fortune 500 buyer and a global facilities management (FM) supplier.

To identify the processes through which boundary spanners at the

\footnotetext{
* Corresponding author.

E-mail addresses: kristof.stouthuysen@vlerick.com (K. Stouthuysen), alexandra.vandenabbeele@kuleuven.be (A. Van Den Abbeele), j.van.der.meer-kooista@rug.nl (J. van der Meer-Kooistra), filip.roodhooft@econ.kuleuven.be (F. Roodhooft).

${ }^{1}$ According to Dekker (2008), buying companies play a pivotal role in the MC design process as they determine the strategy and activities of buyer-supplier relationships and decide about their continuation or termination.
} 
corporate and operating management levels in the buying company learn to control and subsequently shape the MCs of a buyer-supplier relationship over time, we draw on the various learning processes discussed in organizational learning theory (e.g., Argote and MironSpektor, 2011; Bingham and Davis, 2012; Huber, 1991; Zollo and Winter, 2002). In addition, we draw on role theory (e.g., Biddle, 1979; Floyd and Lane, 2000; Janowicz-Panjaitan and Noorderhaven, 2009), which argues that boundary spanners at different management levels have different foci, which leads to differences in learning processes.

Our study yields a number of new insights on the development of MCs over the course of the buyer-supplier relationship. First, by focusing on learning to control over time, our study contributes to the literature on MC design in inter-organizational relationships. Prior research on MC design, which draws more on TCE, takes a comparative statics view and implicitly assumes that inter-organizational relationships tend to be stable over time (e.g., Baiman and Rajan, 2002; Costello, 2013; Dekker et al., 2013), or when a challenge to an interorganizational relationship arises, the contracting parties instantaneously reach a new equilibrium (e.g., Kamminga and Van der Meer-Kooistra, 2007; Langfield-Smith and Smith, 2003; Vélez et al., 2008). Our findings suggest otherwise. In particular, we find that MC design is a learning process that is ongoing over time.

Second, whereas prior management literature focuses on learning through trial and error, we shed light on other processes through which managers of a buying company learn to control their buyer-supplier relationship. We show that these managers learn to control not only through trial and error as a result of repeat interactions with their supplier, but also from third parties (including the partner). They actively seek advice from external sources, as well as from experimentation, in which they deliberately test different scenarios aimed at uncovering causal relationships to identify potential ways to improve control. We also expand the management literature, which focuses solely on contractual controls (e.g., Ariño et al., 2014; Mayer and Argres, 2004; Vanneste and Puranam, 2010), by studying changes in the package of contractual and non-contractual controls that aim to align incentives and facilitate coordination over time.

Finally, ours is one of the first studies to explore, consistent with role theory (e.g., Floyd and Lane, 2000; Janowicz-Panjaitan and Noorderhaven, 2009), how boundary spanners' roles influence the focus of what they learn. More specifically, we show that corporate managers' more strategic perspective leads them to focus on capturing rents from the relationship (i.e., reducing appropriation concerns), whereas operating managers' involvement in the day-to-day workings of the relationship leads them to focus more on the coordination of activities and on communicating about adjustments that may be needed (i.e., reducing coordination requirements). Thus, because of their different roles, corporate and operating managers focus their learning on different aspects of the MC package and as a result implement different controls. The role analysis also reveals that MC design is affected by cross-level learning resulting from lessons learned at the operating level being discussed with managers at the corporate level.

The article is structured as follows. In Section 2, we review the literature on how managers of a buying company learn to design the MCs of their buyer-supplier relationship over time. In Section 3, we discuss our research design. In Section 4, we present our longitudinal case study and describe how the learning processes in the buying company, as well as the roles of the different management levels involved, lead to MC development. In Section 5, we summarize our findings and conclude.

\section{Theoretical background}

\subsection{MC design in buyer-supplier relationships: A comparative static view}

Building on TCE and organizational theory, researchers suggest there are two types of transaction risks when buyers engage in long- term buyer-supplier relationships: appropriation concerns and coordination requirements (e.g., Dekker, 2004, 2008; Dekker et al., 2013; Ding et al., 2013; Gulati and Singh, 1998; Vélez et al., 2008). Appropriation concerns are the buying company's worries about its ability to capture a fair share of the rents from the relationship (Dekker, 2004; Gulati and Singh, 1998). Such concerns arise as a function of transactional and relational characteristics, all of which aggravate the potential for moral hazards or opportunistic behaviour, which cause difficulties for monitoring the supplier's performance and increase the risk of opportunistic behaviour. Coordination requirements reflect the anticipated complexity of decomposing tasks among buyer and supplier, along with ongoing coordination of activities across organizational boundaries, as well as related communication and decisions (Dekker, 2004; Gulati and Singh, 1998). A higher level of task interdependence increases partners' mutual reliance and creates a need for coordination and adaptation (Abernethy and Vagnoni, 2004; Dekker, 2008; Tomkins, 2001).

Managers use MCs to reduce these transaction risks (Dekker, 2004; Dekker et al., 2013; Ding et al., 2013; Hoetker and Mellewigt, 2009; Vélez et al., 2008). Buying companies facing larger appropriation concerns and/or coordination requirements are likely to prefer more complex MC packages with a large number of controls that are specified in detail (Dekker, 2004, 2008). The literature on inter-organizational relationships assumes that the parties' managers know how to design effective MCs at the outset of their relationships (Caglio and Ditillo, 2008). It also argues that when the nature of the relationship changes-thus changing the transaction risks-MCs also change (see, e.g., Kamminga and Van der Meer-Kooistra, 2007; Langfield-Smith and Smith, 2003). As such, research has commonly taken the "discriminating alignment" approach in which the parties' managers are assumed to know the most efficient controls and to dynamically adjust them in response to changing transaction risks.

An alternative view holds that, due to bounded rationality (Williamson, 1985, 1996), the parties' managers are not able to foresee all possible future contingencies under which transaction risks can emerge (Anderson and Dekker, 2014). MCs established at the outset of a buyer-supplier relationship is thus unavoidably incomplete, and managers are likely to adapt and change MC design over time. Previous research adopting a comparative static approach has largely overlooked the way parties' managers learn to design and adapt their MCs during their relationship.

\subsection{MC design in buyer-supplier relationships: the role of learning}

Recent management literature generally focuses on trial-and-error learning as an important process through which managers design MCs. Such learning occurs when a party changes its subsequent controls in response to preliminary controls that worked inadequately (Mayer and Argyres, 2004). Hence, in trial-and-error learning the primary drivers for MC design are problems managers actually encounter, not potential problems.

While a vast amount of management studies have emphasized that trial-and-error learning is a primary driver of MC design (e.g., Dekker and Van den Abbeele, 2010; Mayer and Argyres, 2004; Ryall and Sampson, 2009; Vanneste and Puranam, 2010), other management scholars have argued that this misses the potential existence of other organizational learning processes (Ariño et al., 2014; Lumineau et al., 2011). In addition, in a context in which transaction tasks are complex, the environment is new, or when strategic objectives otherwise need to change, reliance on trial-and-error learning alone quickly becomes hazardous (Kloot, 1997). Such excessive reliance could then lead to MC improvements that are too incremental.

Drawing on organizational learning literature (e.g., Argote and Miron-Spektor, 2011; Bingham and Davis, 2012; Huber, 1991; Zollo and Winter, 2002), we suggest that parties can also learn about MC design from advice from third parties and/or by experimentation. Learning 
from third parties is a process in which managers learn from advice given by external (legal or consulting) firms or members of an industry association (Bingham and Davis, 2012). People seek advice in order to improve their judgment (see, e.g., Knechel and Leiby, 2016), to build confidence and to make their judgment appear more justifiable (Heath and Gonzalez, 1995), and also to share risk or diffuse responsibility for consequential decisions (Harvey and Fischer, 1997).

In our study, we examine the question of third-party advice primarily from a learning point of view, as a way for managers to acquire knowledge and better identify MC design solutions. A potential drawback of reliance on third parties, however, is that a company's knowledge may partially reside in the company itself and may never be articulated if the company is dependent on third parties (e.g., Argyres and Mayer, 2007; Bingham and Davis, 2012).

Another interesting learning process is experimental learningcontrolled situations that individuals use to create new knowledge by testing causal propositions (Cook and Campbell, 1979). Organizational learning scholars argue that managers can gain knowledge and insights through deliberate, small-scale tests, generally conducted "offline" (Argote and Miron-Spektor, 2011; Zollo and Winter, 2002). Managers learn in this way through direct experience, not through external parties. While this is similar to learning by trial and error, the intentional nature of experimental learning sets it apart. That is, when managers learn through experiments, variation in conditions is planned and intentionally introduced in order to produce insights. Several management accounting researchers have argued that MCs themselves may play an important role in promoting curiosity and experimentation (e.g., Free, 2007). This might be the case, for example, when a buyer (and/or a supplier) tries to interpret and make sense of past performance data, and makes an explicit effort to test causal propositions and create new knowledge by performing scenario and sensitivity analyses. These "thought experiments" (Ricoeur, 1984) may then enable a buyer's managers to consider new controls and change the currently available practices. A possible disadvantage of such experimental learning, however, may be that the (theoretical) insights cannot always be quickly incorporated into real-life activities (Bingham and Davis, 2012).

\subsection{Learning to control at different management levels}

Organizational learning theory holds that learning can take place at different levels. A starting assumption about learning levels is that insight and innovative ideas occur to individuals rather than to organizations (Crossan et al., 1999). Yet knowledge generated by individuals does not come to bear on the organization independently. To this end, ideas need to be shared, actions taken, and common meaning developed (Edmondson, 2002).

Our focus on boundary spanners builds on this premise. Boundary spanners are the individuals most relevant to the implementation and management of a buyer-supplier relationship; they potentially have the power to influence the MC package (Dekker, 2016). Boundary spanners occupy different positions in the organizational hierarchies of their respective organizations. The existing literature especially stresses the systematically different roles of top managers compared to their colleagues at lower levels in the corporate hierarchy (Janowicz-Panjaitan and Noorderhaven, 2009; Janowicz-Panjaitan and Krishnan, 2009). We therefore distinguish between boundary spanners at two levels of the organizational hierarchy and also between the kinds of learning that take place at these two levels. Hence, in addition to asking "who learns?" and "how do they learn?", we ask "what is learned by boundary spanners at the corporate and operating management levels?"

To this end, drawing on role theory (Biddle, 1979; Floyd and Lane, 2000; Janowicz-Panjaitan and Noorderhaven, 2009), we take a close look at how the role of boundary spanners may affect the content of their control knowledge. A role is the set of behaviours that others expect of individuals in a certain context (Floyd and Lane, 2000). The expectations may be stated overtly, in terms of written demands for and assessments of specific behaviours, or they may take the form of covertly held prescriptive norms, descriptive beliefs, and priorities (Duplat and Lumineau, 2015). Such expectations define the modal behaviours of a role and form the basis of individuals' unique role interpretations (Floyd and Lane, 2000). The distinct roles of boundary spanners at the corporate and operating levels strongly influence the focus of attention when learning about more effective controls, as these roles often tend to be quite different from each other.

At the corporate level, boundary spanners are executive managers who have the power to influence the overall strategic direction of buyer-supplier relationships (Janowicz-Panjaitan and Noorderhaven, 2009; Janowicz-Panjaitan and Krishnan, 2009). These decision makers play a crucial role in the formation of new buyer-supplier relationships (Faems et al., 2008; Lumineau et al., 2011). They also frame their company's strategic intentions with respect to the buyer-supplier relationship, play a dominant role in designing a contract that stipulates the boundaries and parameters of this relationship and monitor its overall performance (Floyd and Lane, 2000). When necessary, they are engaged in dispute resolution, renegotiation of contractual arrangements, and litigation preparation.

Given their role-based focus of attention, we expect corporate boundary spanners to focus on acquiring control knowledge that aims to reduce appropriation concerns. They will place high value on including MCs that measure and reward performance and prioritize protection due to specific investments. With respect to coordination requirements, we expect corporate boundary spanners to pay attention to MCs that set the boundaries within which the activities have to be coordinated on a day-to-day basis. Such controls could also positively impact collaborative performance (see, e.g., Dekker, 2004; Hoetker and Mellewigt, 2009).

Operating boundary spanners, on the other hand, "provide the daily linking mechanism across organizational boundaries" (JanowiczPanjaitan and Noorderhaven, 2009, p. 1027). In this role, they are responsible for the everyday implementation of the relationship's agreedupon objectives, and carry out the task of coordinating the day-to-day activities (Hamel, 1991; Van der Meer-Kooistra and Scapens, 2015). For example, in product co-development projects the partners' engineers, and not the partners' corporate managers, carry out the joint task of developing a new product (Van der Meer-Kooistra and Scapens, 2015). Likewise, in global buyer-supplier relationships, it is the country and regional managers who are responsible for carrying out the relationship's objectives set by corporate managers.

Consistent with their role, operating managers will place high value on the acquisition of knowledge that helps them develop operating routines to better guide the interactions between the partners across boundaries (Argyres and Mayer, 2007). To be able to manage the individuals involved in the daily activities, operating managers need regular insight into their performance. Such insight is also needed for ensuring that performance targets are met. Operating managers have a role in informing corporate managers about potential and actual coordination and appropriation risks or suggesting opportunities to execute the activities more effectively, which may require changes in the contractual controls (e.g., Van der Meer-Kooistra and Scapens, 2015).

We expect that, to learn to control buyer-supplier relationships, buying companies will learn at both the corporate and operating levels. Learning to control at a single level (with corporate managers focusing on control knowledge that supports their decision-making at a more strategic level and operating managers on control knowledge for managing day-to-day activities) could result in transaction risks going uncovered. In addition to learning to control at both levels, we expect that learning to control at one of the levels could trigger such learning at the other level. Such cross-level learning, where the learning of managers in one level can affect that of managers at the other level, could be stimulated by creating a linking pin position between the corporate and operating levels (see Van der Meer-Kooistra and Scapens, 
2018).

\section{Research method and case study design}

The purpose of this study is to gain a more detailed understanding of how boundary spanners at two distinct levels of management-corporate and operating-learn to control and subsequently shape the MCs of buyer-supplier relationships over time. To answer our research question, we conducted a six-year (Y1-Y6) longitudinal case study of a buyer-supplier relationship, which allows us to get detailed insight into the learning processes at the corporate and operating management levels and the outcome of these processes in the course of the buyer-supplier relationship. According to Eisenhardt (1989), a case study is a theoretical activity-it tries to position and interpret practical phenomena to contribute to theory. Our case study aims to deepen existing theory about how buying companies learn to control their buyer-supplier relationships.

Our focal buying company, MultiGoods (MG), is one of the biggest consumer goods companies in the world. In Y1, MG established a longterm facilities-management outsourcing agreement with FacilityNet (FN), a global FM supplier. As buying companies play a pivotal role in the MC design of buyer-supplier relationships (see section 1), we focused our study on how the boundary spanners within MG learned to control the MG-FN relationship during the entire period (Y1-Y6). We formally ended our investigation in the middle of Y6, when modifications to the MC package had stabilized.

The MG-FN relationship enabled MG to outsource more than 750 FM activities, ranging from simple to more complex, to a new supplier. Examples of simple FM activities included services such as cleaning, reception services, catering, and lawn and road maintenance. Examples of more complex FM activities included the operation and maintenance of MG's technical equipment, the provision of technical safety, the design and coordination of building new laboratories and pilot plants for MG, energy management, space management, and the guarantee of business continuity. MG viewed the outsourcing agreement with FN as an arrangement in which the systematic management of all FM activities was FN's main responsibility, and developed a set of homogeneous controls to govern this systematic management responsibility. Because FN wanted to become a market leader in organizing global FM solutions, MG had strong bargaining power. MG largely determined the relationship's strategy and tightly controlled the relationship with FN.

We chose the MG-FN case for three reasons. First, because MC formed a central component of MG's outsourcing strategy, the company's managers presented clearly articulated and documented conceptualizations of the range of formalized controls they applied and their motivations for implementing them. Second, because existing theoretical insights into the effects of learning within a buying company on MC design choices are limited, we chose a case in which these learning effects were expected to be substantial. As this was the first time MG and FN had done business together and the relationship faced multiple risks in terms of appropriation concerns and coordination requirements, the potential for learning appeared significant. A final reason was that we had good access to MG's and FN's corporate and operating managers in a number of countries.

The main instrument we used to gather data was semi-structured interviews with both partners' corporate boundary spanners and operating boundary spanners (see Appendix A for further details on informants). Although we focused our study on the learning processes within MG, we also interviewed the supplying company's managers because having an insight into their view on the MCs applied by MG helped to understand the development of the MCs initiated by MG's boundary spanners. We collected our interview data in two phases. The first was a retrospective approach in which we compared Y1 and Y2. Although retrospective studies are vulnerable to respondent bias (Leonard-Barton, 1990), several aspects of our data collection ensured the accuracy of these reports. Precautions included asking our informants to focus as much as possible on facts rather than opinions (Leonard-Barton, 1990). We also gave informants the free report option, which encouraged them to let us know when they could not recall some detail. Although this approach meant we lost some data and had less information available for analysis, it increased the accuracy of the responses we did gather. Finally, whenever possible, we attempted to verify individual reports by asking multiple participants similar questions. The second phase consisted of real-time data collection from Y3 to Y6.

In total, we conducted 31 formal, semi-structured interviews, each lasting about $90 \mathrm{~min}$ (for the interview protocol, see Appendix B). 27 Interviews were recorded and transcribed in full. For 4 interviews, we only took notes and used them for drafting interview reports. All interviewees received one or more of these reports. This enabled them to give us feedback about any misunderstandings and omissions.

In addition to the interviews, we collected corporate documents related to the creation of the relationship. We also read many newspaper articles dealing with developments within the FM sector, and developments within the MG-FN relationship. The use of multiple sources of evidence enabled us to cross-check findings, making our conclusions stronger.

To facilitate data analysis and interpretation, we first constructed a chronology of the relationship's key historical events. Next, we coded the interview transcripts and other documents, based on an initial list of codes from the perspective of our theoretical background. Throughout this process, and dictated by the data, also some new codes emerged or others were revised. In the following stage, we used matrices to display the coded data. This process enabled us to identify the learning processes MG's boundary spanners relied upon to inform their MC design choices over time. In addition, we were able to analyse how boundary spanners' different roles directed their focus of learning, which subsequently influenced the evolution of the MCs.

\section{The case study}

In this section, we describe and analyse the learning processes by means of which MG learned to control the buyer-supplier relationship. Fig. 1 summarizes the MC design and knowledge acquired over time in the MG-FN relationship.

\subsection{Learning to design the contractual MCs}

Negotiations between MG and FN began in the spring of Y1. From MG, only corporate managers including the global services manager, the procurement VP, and the VP of finance were involved; they were considered to be MG's strategists. Their job was to make sure that the relationship as a whole delivered the objectives they had set. In the interviews, MG's corporate managers stressed that, during these negotiations, they acted as the dominant partner, presenting the relationship's contract largely as a take-it-or-leave-it proposition. Because FN was eager to establish a position as an industry leader, it accepted most of the contractual controls that MG dictated. At the end of Y1, the contract was signed.

What is notable here is that this was the first time the two companies had done business together, and MG's corporate managers had little experience in drafting global contracts in the FM industry. Moreover, as the VP of finance added, "Given our future dependence on FN's performance, a key cooperation concern for us was that FN would not behave as agreed. The contract as such would play a fundamental role in taking out all the risks that relate to FN's potential self-interested behaviour. To build such a contract, we needed expert advice". A legal firm was contacted and its lawyers helped MG's corporate managers develop a contract that would foster FN's commitment to the deal.

Based on the legal experts' advice, the contract stipulated that while FN would become responsible for providing an integrated approach to maintaining, improving, and adapting the buildings and other asset 


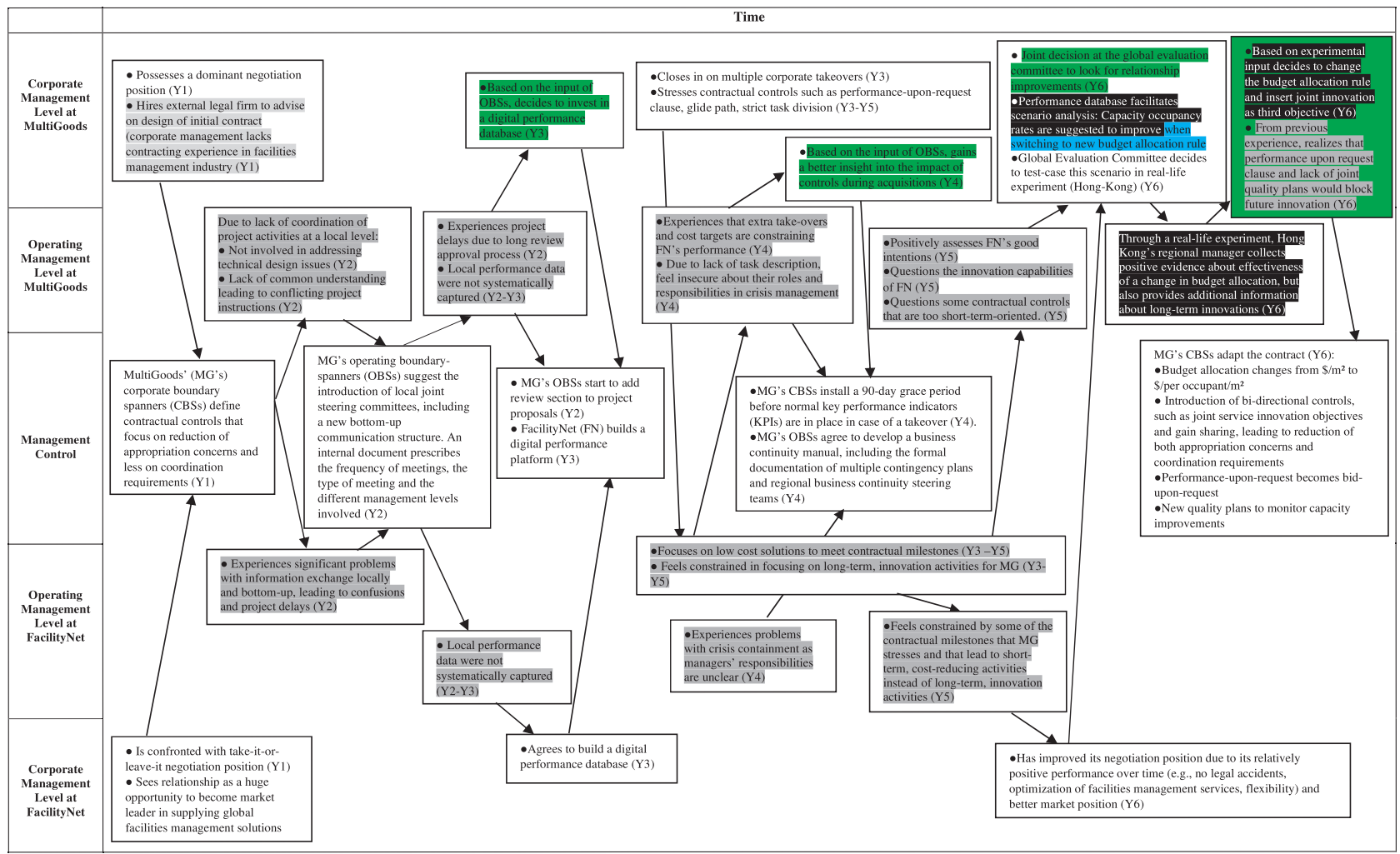

Fig. 1. fx1Overview of the processes through which boundary spanners at the corporate and operating management levels within MultiGoods learn to control and subsequently shape the management controls of the supplier relationship with FacilityNet. Learning processes legend:

Learning from advice from a legal firm/ from the partner:

Learning through trial-and-error

infrastructure, MG would retain ownership of the assets. The contract also stipulated that it was FN's "sole responsibility" to manage the execution of a list that specified more than $750 \mathrm{FM}$ activities. In addition, in case of conflict, legal action was permitted. Here, the legal firm also advised MG to add an "as is where is" clause, which eliminated MG's duty to disclose latent material defects, protecting it from lawsuits by FN for damages incurred by MG's failure to disclose such defects. Furthermore, since MG seconded some of its own staff to FN and FN would, over time, get to know the features of MG's various installations and systems, the contract stressed the confidential nature of the technological and commercial information being exchanged. The contract also stressed the preconditions regarding the subcontractors to be hired by FN (e.g., conditions concerning financial position, safety, environment, experience and skills, the protection of commercial and technical know-how). Finally, to guarantee fair pricing and transparency in the costs of the performed services, the contract specified a rule for openbook accounting.

At the outset, the aim of MG's corporate managers was simply to get the best value out of this relationship. In the end, from the exchanges with the legal firm, two underlying, strategic goals were identified: to lower costs and to maintain (or increase) the level of service quality. As the legal firm had expertise in a wide range of governance solutions for facilities-management outsourcing, they helped MG's corporate managers boil down these strategic goals into seven key performance indicators (KPIs): uninterrupted operations, legal compliance, cleanliness, project completion days, overall customer satisfaction rates, a decrease in energy consumption, and spending brought into accordance with the approved budget. The contract also codified target percentages and performance standards for these KPIs.

Based on the legal firm's advice, MG also contractually stipulated that annual FM budgets were calculated on a cost-per-square-footage rule $\left(\$ / \mathrm{m}^{2}\right)$, so that the larger corporate sites to be managed took up more of the allocated budget. As cost reduction was an important strategic goal, the legal firm suggested linking a part of FN's management fee to a yearly pre-agreed price-reduction target. Following this recommendation, the contract included a "glide path"-a predetermined schedule that required FN to reduce total FM expenses by $3 \%$ per year. $^{2}$ Finally, to monitor FN's performance, the contract stipulated the appointment of a global evaluation committee (GEC) including corporate boundary spanners of both transaction partners. This committee would meet to monitor FN's global performance and discuss the strategic direction of the relationship. A "performance-upon-request" clause further ensured MG that it could oblige FN to carry out FM activities that were not specified in the contract.

Reflection on designing the contractual controls. Only corporate managers were involved in the negotiations. As MG's corporate managers had little experience with drafting global contracts in the FM industry,

\footnotetext{
${ }^{2}$ If FN's total expenses, as invoiced to MG in any contract year, exceeded the approved annual budget (a "budget overrun"), the incentive compensation that was payable as part of FN's management fee would be reduced by the amount of the budget overrun.
} 
they learned from the advice of external legal experts how to design the contractual controls for the buyer-supplier relationship with FN (i.e., learning from the advice of an external party). In the interviews, MG's corporate managers referred to the controls included in the contract as "mechanisms that allowed monitoring the global performance of the supplier" (procurement VP). The interview data show that the contract hardly included controls specifying the way FN was obligated to achieve these targets. Nor did it make clear MG's role. Further, despite the fact that the contract included the establishment of a GEC, it did not stipulate any of the cornerstones of partner communication, such as frequency, content and timeliness. How the relationship would be governed on a more local level was also unclear. It appears that MG's corporate managers' reliance solely on advice from external legal experts caused the contractual controls to focus mainly on the reduction of appropriation concerns and less on coordination challenges.

\subsection{Learning to control the daily FM activities}

The execution of the FM activities started at the beginning of Y2. MG's operating boundary spannerss indicated that the relationship was not as smooth as either party had hoped. In particular, coordination challenges, in terms of improving communication, along with clarifying task responsibilities, seemed to have caused most of the problems encountered during the execution (Y2-Y5). Field study data suggest that efforts to mitigate those challenges mainly took place at the operating management level through trial-and-error learning. This process is described in detail below.

Improving communication and information exchange. A few months into Y2, operating managers of both companies discovered that the contract did not include arrangements for either bottom-up communication or governance at a local level between operating boundary spanners from both parties. Instead, the contract only mentioned controls at the corporate level. Yet many problems emerged at the local level. For example, while in the GEC corporate managers aligned the relationship in terms of big strategic projects such as the building of new laboratories and pilot plants for MG, the GEC did not pay any attention to the further coordination of the project activities at the local level and the follow-up of these projects. For MG it was mainly FN's responsibility to make sure that the projects were executed and coordinated with the various subcontractors (i.e., specialized construction firms) in an effective way. However, when these projects then took off, it became clear to MG's operating boundary spanners that FN's managers also required the help of their local managers and engineers to solve a variety of problems, such as with the design, construction or renovation of laboratories. After all, MG's local engineers could offer guidelines and insight into unique local technical needs, such as with the design of laboratory ventilation, special furnishings and fume hoods. But as communication and information exchange on technological issues were largely absent, engineers and managers of both MG and FN had difficulties solving issues together effectively. Moreover, the lack of adequate communication and weak sharing of information meant that even MG's local engineers and managers often did not have a common understanding of some of the construction projects' specifications. This lack of common understanding often resulted in FN's operating managers receiving conflicting instructions from MG's local managers in terms of project time, cost, design or material requests. This caused confusion and project delays.

These problems were largely resolved by MG's operating boundary spanners who decided to initiate local joint steering committees that would force both companies' operating boundary spanners to regularly exchange information on operational issues, including constructionand infrastructure-related FM issues. A newly developed bottom-up communication structure also improved the exchange of information among operating and corporate boundary spanners. An internal document, which became part of MG's operating procedures, was published online and prescribed the frequency of these different meetings (weekly, monthly and quarterly), the type of meeting (on site, off site, conference call, etc.), and the different managers involved (site, country, region, headquarters).

While local joint steering committees largely solved the problem of conflicting instructions and design issues, they also had an unanticipated side effect: a lack of clearly described decision-making and approval procedures caused delays in execution of new construction projects. With the increase in the number of people involved came an increase in the review loop for project decision-making and approvals. It was also not always clear who had approved for which design change. This problem was solved by MG's operating boundary spanners who added a revision history section to all communications. This section was rolled out globally and prevented MG's and FN's managers from unwittingly approving an outdated version of the document.

Intriguingly, further control modifications were implemented in response to the appearance of other communication problems. In particular, while the main goal of the local steering committees was to exchange information and insights at a local level, a significant amount of local performance data was not yet captured. Therefore, at the start of Y3, operating boundary spanners at the regional level signalled the need for the development of a digital platform to bring together large pools of performance data. Somewhat later, MG's corporate management approved this investment and FN agreed to build a digital performance data platform that allowed both partners to access the realtime status of all performance metrics on a local and aggregated base. This allowed them to make better decisions when critical situations arose.

Clarifying task responsibilities. During Y3, MG closed in on two corporate takeovers. The exertion of the "performance-upon-request" clause obliged FN's operating managers to take care of the FM activities of the newly acquired plants. This increase in workload frustrated them. Other contractual milestones, such as the "glide path", also pushed FN's operating managers to focus on cost control. Nevertheless, FN's operating managers tried to "keep MG happy" (site manager, FN) by complying with these commitments, even if this meant delivering poorquality FM solutions. One of the interviewees at MG also experienced this conflict of interests: "While FN generally agreed to perform. . so as to meet the requirements of project time, reduce costs and at the same time improve quality without safety issues, we noticed that the increase in number of plants to be managed, and renovating and maintaining increasingly complex structures were particularly challenging with rising costs in labour and materials."

In the winter of Y3, MG's senior management announced a further phase of acquisitions. As a result, discussions on the work floor became more contentious. MG's and FN's operating managers were both of the opinion that the extra take-overs were constraining FN's performance under the current control structure, which granted FN no flexibility in executing FM in the newly acquired plants. In the end, MG's operating managers "escalated this issue to the executive level". They successfully convinced MG's corporate managers to agree that "for newly acquired plants, FN would receive a 90-day grace period before the KPIs described in the contract were put in place". This grace period of three months allowed FN the flexibility to get familiarized with the new infrastructure and FM activities of the newly acquired plants before the existing KPIs and performance targets were applied. This grace period was added as a formal condition to the KPI dashboard. Hence, based on MG's operating managers' learning, corporate managers developed more insight into the way contractual controls impacted FN's performance during acquisitions periods.

A final problem that caused disputes in terms of task responsibility was that MG's corporate managers had spent little time planning upfront for potential disruptions and calamities-under the assumption either that this was FN's responsibility or that they could not plan for what they could not anticipate. As a result, when several of MG's offices were flooded in Y4, operating managers of both partners felt insecure about each other's roles in fighting this crisis. FN's operating managers 
ultimately took the lead, but the lagging response created unnecessary material damage.

Soon afterwards, MG's regional managers suggested developing a business continuity manual. This existed alongside the contract, providing formal documentation on the development of multiple contingency plans and the development of various regional business continuity steering teams with responsible persons from both companies. Through this manual, both MG and FN provided guidance for crisis management practices for their members with the clear description of joint responsibilities, such as the commitment of MG's operating managers to join on-site crisis management training sessions organized by FN's operating managers. In addition, the manual stipulated the initiation of a single point of contact at each corporate site that was available for emergencies year-round, 24/7. The manual became part of MG's control practices and was implemented globally.

Reflection on designing controls for daily FM activities. After the FM activities were started, MG's operating boundary spanners soon discovered that controls were lacking for directing FN's daily FM activities. No controls were established for communication and exchanging information between companies, and the responsibilities for additional tasks resulting from acquisitions and emergencies were not clear. Consistent with their role, MG's operating boundary spanners focused mainly on designing controls that facilitate coordination. Primarily through trial-and-error learning, MG's operating boundary spanners succeeded in improving communications between, and clarifying the responsibilities of MG's and FN's managers at the local level. MG's operating boundary spanners also established a communication structure between operating and corporate boundary spanners. This structure enabled MG's operating boundary spanners to discuss their lessons learned through trial and error with the corporate boundary spanners. The interview data show that by discussing local-level learning with the corporate boundary spanners, the operating boundary spanners could convince them to take decisions that helped smooth relations. Examples of such cross-level learning decisions (i.e. where the corporate management level learns from the operating management level) included investing in a digital performance data platform, developing a business continuity manual, and introducing a grace period before implementing KPIs.

\subsection{Renegotiation of contractual controls}

While the partners' operating managers focused on resolving coordination problems, in time they also felt that performance issues recurred. At the end of Y5, an MG regional manager expressed MG's mild discontentment: "While we were relatively satisfied with the services we got. . it did not blow our minds. Moreover, over time, a few of our managers had the opinion that while FN did the same things in better ways, they never did anything in a completely different way". In a similar vein, another regional manager questioned FN's innovation capabilities and wondered what time would bring, since "the time for picking the low-hanging fruit. . is over". Through discussion and regular cross-border interaction, though, these managers were realistic enough to question the long-term impact of some contractual controls which made FN's managers overly focus on short-term, cost-reduction activities, rather than long-term, innovation activities. Hence, we also observed that operating boundary spanners served as an important trigger for corporate boundary spanners to learn that managers on this local, operating level experienced the negative impact of certain controls on FN's ability to introduce FM innovations and subsequently took the initiative to inform MG's corporate managers.

In the winter of Y5, the GEC, including corporate boundary spanners from both $\mathrm{MG}$ and $\mathrm{FN},{ }^{3}$ started a discussion on how to redirect the

\footnotetext{
${ }^{3}$ By this point, MG's managers considered FN much more of an equal negotiation partner because the latter had built up its market position and had
}

relationship and parts of its contract. Notably, the digital performance data platform played an important role in facilitating this discussion. Offering details of every project that FN was managing for MG, the platform was a repository for records of all incidents and events related to the previous 2.5 years and allowed filtering past data for trends and performance outcomes.

One such trend was that the capacity occupancy rates (CORs) for MG's corporate sites in different regions of the world had been decreasing for the last two years (e.g., CORs Asia: $87 \% \rightarrow 78 \%$; CORs Europe, Middle East and Africa: $81 \% \rightarrow 71 \%$; CORs Americas: $76 \% \rightarrow$ $70 \%)$. CORs measured how full the office space was compared to its capacity and helped to assess the affordability of infrastructure. A decrease in COR levels across regions thus highlighted the underuse of infrastructure and raised questions about the effective use of office space.

While FN's VP of operations agreed with the optimization of COR levels as a way to generate more innovation, she also noted that this would require a change in current budget allocations. Until then, budgets were based on the $\$ / \mathrm{m}^{2}$ rule. Hence, managers were not incentivized to find solutions to increase COR levels as budgets were allocated by space volume, not space utilization. To solve this issue, the VP of operations proposed basing budgeting on $\$$ per occupant per $\mathrm{m}^{2}$ instead of $\$$ per $\mathrm{m}^{2}$.

While many members of the GEC saw value in this idea, they remarked that translating a theory into practice can be risky due to many built-in assumptions, including the expectation that changes in budgeting will drive managers to innovate. MG's VP of procurement therefore suggested first testing this change and monitoring its actual outcome. Most committee members broadly supported this idea of a real experiment. Rather quickly, it was agreed that corporate offices in Hong Kong should serve as a test case. Hong Kong was interesting because its office space was among the world's most expensive; the GEC also trusted MG's highly experienced regional manager there.

After only four months, it was clear that the change in budget allocation indeed incentivized FN's local managers to focus more on the optimization of CORs. By paying more attention to the functionality of offices, creating desks that could be used by different employees, redesigning workspaces to make them multi-functional, and digitizing certain processes to increase employee flexibility, utilization levels of the infrastructure improved again. In total, COR levels in Hong Kong offices increased by $7 \%$ on average. At the same time, the experiment improved FN's understanding of the available space and MG's employees' real demand for different types of rooms. This understanding led to the first steps in the development of a digitized timetabling programme and a space-charging programme that allowed for differential charging for different times of the day or week aimed at addressing overcrowding at peak times and underuse at others.

While in favour of this budgetary change, MG's regional manager in Hong Kong also warned against overly focusing on one type of innovation: "You have to be careful, because when FN's engineers came up with new solutions to optimize COR levels again, which I think is a very positive thing, and they came up with three or four potential solutions-and now I am being a bit provocative-they thought the job was over. That is dangerous, because the job of innovation is never over, right?" Based on the experiment and the behaviours observed, the regional manager therefore stressed that joint cooperation with FN's engineers would become increasingly important for achieving further innovation.

The knowledge acquired during this experiment served as an important input that influenced the corporate managers' decision to revise parts of the contract, in May Y6. The result was a combination of specific changes linked to the further guarantee of the optimization of COR

(footnote continued)

proven to be a trustworthy partner. 
levels, and broader changes linked to the generation of future service innovation. With regard to the former, a new budgeting rule (\$/occupant $/ \mathrm{m}^{2}$ instead of $\$ / \mathrm{m}^{2}$ ) was established.

Based on the input of the Hong Kong manager, MG's corporate managers also decided to initiate a third strategic goal in the revised contract which referred to the generation of more "joint service innovation". To further strengthen this joint innovation objective, the corporate managers also agreed to include a gain-sharing system to provide a prospect of fair rewards for partners' contributions to joint efforts. As MG's VP of global services commented: "the goal of this gainsharing system was to establish a common basis of interests again and motivate employees of both companies to work smarter as a team rather than just working harder. So, we wanted to take a wider approach on future FM innovations, but not too wide, of course-in the end it was still the responsibility of FN to manage new projects from start to finish".

Based on past experience, MG's corporate managers also changed the "performance-upon-request" clause into "bid upon request". As a result, FN was no longer obliged to satisfy all of MG's extra FM project demands and could focus its resources more strategically. Moreover, as quality issues appeared over time, MG's corporate managers decided the innovation process would be further managed by quality plans developed by FN, and that MG would annually audit the use and performance of these plans.

Reflection on the renegotiated contractual controls. The renegotiation of the contractual controls was triggered by the lessons learned by trial and error at the operating level. MG's operating managers discussed these lessons learned with MG's corporate managers, who subsequently started a discussion about this issue in the GEC. FN's corporate managers suggested changing the budgeting system. After having successfully tested this change at the local level, the corporate managers decided to revise the budgeting system described in the contract and, moreover, to add a gain-sharing system. Hence, we observe learning by trial and error at the operating management level, cross-level learning from the operating management level to the corporate management level, learning from the advice of the partner FN, and learning by experimentation at both the operating and corporate management levels. In addition, we observe that learning by trial and error at the corporate management level led to changes in the contractual controls-see the change in the "performance-upon-request" clause into "bid upon request", the introduction of quality plans, and to audit their use and performance each year.

The foregoing analysis enables us to conclude that, through experimental learning, it was MG's corporate managers, guided by their role-based focus of attention (in accordance with FN's corporate managers), who adjusted the strategic intent of the relationship. The interview data also show that in revising the strategic intent of the relationship, the digital performance data platform played an important role. As such, controls themselves played a role in stimulating experimental learning. In contrast to what we expected, this experimental learning happened through an actual test case (and not offline) with the involvement of operating managers. This learning also provided input into controls that not only reduced further appropriation concerns but at the same time stimulated coordination, as in the joint innovation objective and gain-sharing system.

\section{Discussion and conclusions}

Informed by the learning processes in the MG-FN relationship, we now discuss the findings of our longitudinal study of this buyer-supplier relationship, describing the case findings, presenting conclusions, and identifying future directions.

\subsection{Case findings}

Our study of the MG-FN relationship shows that MG took the lead in designing the MC of this relationship. Our study also demonstrates that MG was not able to develop an overall MC package at the outset of the relationship. As MG's corporate managers had no experience with developing an outsourcing contract for the management and execution of more than $750 \mathrm{FM}$ activities worldwide, MG's corporate managers asked a legal firm to help them develop the controls to be included in the contract. The contractual controls that the legal experts advised focused primarily on controls that could mitigate expected appropriation concerns. Hardly any attention was paid to controlling the daily FM activities, which required adequate communication and exchange of information between the partners' operating managers and clarity about each other's responsibilities. After the execution of the FM activities was started, MG's operating managers learned by trial and error how to develop controls for controlling the daily FM activities. Clearly, both MG's corporate and operating managers were unable to foresee all appropriation concerns and coordination requirements related to the MG-FN relationship as assumed in a major stream in the management accounting literature that draws on TCE (e.g., Dekker, 2004, 2008; Langfield-Smith and Smith, 2003; Phua et al., 2011; Vélez et al., 2008). MG's corporate and operating managers needed to learn in the course of the relationship how to develop and adapt the MC package. This finding underlines the management literature in which various scholars argue that learning is a key mechanism to shape and adapt the controls of inter-organizational relationships (e.g., Bingham and Davis, 2012; Mayer and Argyres, 2004; Vanneste and Puranam, 2010).

In contrast to the management literature that claims that trial-anderror learning is the main driver of MC design, our study shows that MG's managers also learned to design and adapt the MC package through other types of learning processes, such as advice from third parties, including advice from the partner, experimentation, and crosslevel learning. Experimental learning in our case took place in a real situation and not offline as described in the organizational learning literature (Argote and Miron-Spektor, 2011; Zollo and Winter, 2002). We also observe that existing controls can stimulate learning processes, such as processes of experimental learning in our case. This observation supports the conclusion of other management accounting researchers that MCs can promote curiosity and experimentation (e.g., Free, 2007).

A major difference between our study and similar studies in the management literature describing processes of learning is that we focus on the design of MC packages, including contractual and non-contractual controls, whereas the other studies investigate the design of separate contractual controls. By looking at separate contractual controls it is impossible to understand how partners control their buyersupplier relationships, for the controls as a whole and not separate controls determine the control of buyer-supplier relationships.

Another finding is that studying learning processes at two different management levels, i.e. corporate and operating levels, allowed us to get an in-depth insight into the focus of the various learning processes and thereby into the contribution of both management levels to the design of the MC package. Our case study shows that corporate managers focus their attention on strategic aspects of the relationship and, more specifically, on reducing appropriation concerns, whereas the operating managers focus on the daily execution of the FM activities and the coordination problems related to executing these activities. As argued by role theory (e.g., Floyd and Lane, 2000; Janowicz-Panjaitan and Noorderhaven, 2009; Janowicz-Panjaitan and Krishnan, 2009), this difference in focus is in line with the roles the two types of managers fulfil. We observe that both types of managers learned different lessons, which led to the design of different types of controls: controls to mitigate appropriation concerns respectively controls to solve coordination problems. All controls were required to create a MC package that could effectively control the buyer-supplier relationship.

In addition, by studying learning processes at two different management levels we were able to identify various processes of cross-level learning. One example is the experience of MG's operating managers that the many acquisitions, which substantially increased the scope of 
FN's activities, worsened FN's performance. In particular "the performance-upon-request" clause obliged FN's operating managers to take care of the FM activities of the newly acquired plants and to meet the KPIs described in the contract. They discussed their worries with MG's corporate managers and suggested introducing a 90-day grace period before the KPIs had to be met. MG's corporate managers accepted the introduction of such a grace period and added it to the KPI dashboard. Another example is the insight of MG's operating managers that existing MCs hindered FN innovating over time. They questioned the long-term impact of some contractual controls, because of which FN's operating managers focused on short-term, cost-reduction activities rather than innovating their FM activities having effects in the long term. Scholars who investigate new product development projects argue that controls have to provide room to manoeuvre otherwise they hinder creativity (Dunk, 2011; Kamoche and Cunha, 2001; Van der Meer-Kooistra and Scapens, 2015). This was the lesson MG's operating managers learned over time and discussed with MG's corporate managers. After a successful experiment with an adapted budget allocation system suggested by FN's corporate managers, ultimately, MG's corporate managers decided to change this system.

\subsection{Concluding remarks, limitations, and directions for future research}

This article has studied how a buying company learns to control its buyer-supplier relationship over time and the role of corporate and operating managers in directing this learning. The article draws on a longitudinal case study of a buyer-supplier relationship (Y1-Y6) in which the buying company learned to control the relationship by means of various learning processes. A longitudinal case study allowed us to follow the various learning processes, the triggers of these processes, the management levels involved, the type and focus of learning, and the effects of the learning processes on the development of the MC package.

The findings show that our study makes various contributions to the existing literature. It demonstrates that prior management accounting research studying the control design of inter-organizational relationships does not offer a complete view of how control decisions are made as this research assumes that the parties are able to foresee the transaction risks (i.e., appropriation concerns and coordination requirements) and shape the MCs at the outset of these relationships (Anderson and Dekker, 2014; Caglio and Ditillo, 2008). Our study proposes a process approach to analyse the MC design choices that adds learning as a critical theoretical mechanism to the bounded rationality assumption traditionally found in TCE-grounded studies. Especially in the case of inter-organizational relationships characterized by high levels of uncertainty, our study shows that the parties need time to learn how to control their relationship. Even when the transaction risks change in the course of a relationship, in the case of high levels of uncertainty it is likely that the parties will not be able to instantaneously identify these changes and their impact on the existing MCs. The parties will need to learn how to react to these changes.

Our study contributes to the management literature in several ways. It points out that parties of buyer-supplier relationships not only learn to control through learning by trial and error (e.g., Mayer and Argyres, 2004), but that they also apply other types of learning processes, such as learning from the advice of third parties, experimentation, advice from the partner, and cross-level learning. In addition, it finds that parties learn to control their buyer-supplier relationships at two distinct hierarchical levels. While much current research is limited to learning at a single (organizational) level (Ariño et al., 2014; Mayer and Argyres, 2004), our analysis addresses this limitation by analysing learning processes of organizational boundary spanners at both corporate and operating levels. By so doing, we are also able to highlight how crosslevel learning between those levels drives the evolution of the MC package. Our study thereby reinforces the importance of including organizational members' roles and perceptions of the transaction in theoretical frameworks aimed at investigating how parties learn to control inter-organizational relationships. Furthermore, our study extends the focus of the management literature on separate contractual controls to the MC package, including both contractual and non-contractual controls.

This study was exploratory and is limited in several ways. First, we are aware that more cases are needed to increase our understanding of how buying companies and their managers learn to control buyersupplier relationships. We are especially interested in cases of buyersupplier relationships in other industries or with different relationship characteristics, such as relationships in which the buying and supplying companies have a balanced bargaining power from the start, or can rely on previous experience. We also studied a successful buyer-supplier relationship, but relationships sometimes evolve in different ways. When a close relationship becomes too costly or risky, a buying company may decide to switch gears and return to engaging only in arm'slength relationships (e.g., Phua et al., 2011) or to go back to self-production again. The learning processes are likely to be different in these settings. Also, in our case, the different management levels took the necessary action to transform their acquired knowledge into MC changes. Future research could explore why some managers learn about specific control challenges without real change while other managers engage in more complete learning to control cycles. Finally, MC studies have stressed that, in addition to formalized controls, trust is also an important (informal) construct that interacts with formalized controls (see, e.g., Vosselman and Van der Meer-Kooistra, 2009). Future research could investigate how buying companies not only learn to control through contracts and formalized controls, but also learn to trust. One could also study how trust at one management level may affect or be affected by trust at other management levels. By taking a more inclusive approach to the MC package, such studies will help us to better understand how buying companies learn to design the MCs of their buyer-supplier relationships.

\section{Appendix A. Interviews}

Interview informants

Interviews

MultiGoods

Role

Corporate boundary spanners

\section{Operations VP}

Finance VP

Procurement VP

Operating boundary Regional authorities: spanners

EMEA, Americas, and Asia heads of sourcing ( 3 people) -Country and small regional managers (3 people)

$\begin{array}{ll}\text { Date } & \begin{array}{l}\text { FacilityNet } \\ \text { Role } \\ \text { May Y6 }\end{array} \\ \text { Chief Operations Officer } \\ \text { November Y4, July Y6 } & \text { VP alliance management } \\ \text { November Y4 } & \begin{array}{l}\text { Operations team global: } \\ \text { February Y3 }\end{array} \\ & \text { Head of Engineering } \\ & \text { Project managers (2 people) } \\ & \text { Regional managers (2 people) }\end{array}$

February Y3, May Y4, December Y5

Country managers in Belgium, USA, Singapore (3 people) February Y3, November Y4, Site managers (3 people) June Y6
Date

May Y6

December Y5

December Y4, May Y6

December Y4, April Y5, May Y6

February Y3, April Y5, May Y6

April Y3, February Y5, June Y6

February Y3, November Y3, March Y4, October Y6 


\section{Appendix B. Issues covered in interviews}

\section{(1) Background information on the respondent}

Could you describe your position at the company?

Are you centrally based or at a specific site?

Have you been involved since the start of the outsourcing relationship?

Do you deal with the day-to-day problems of the relationship or more long-term issues?

\section{(2) Design of the initial contract}

What were the strategic objectives established at the outset of the relationship?

Were you involved in developing the initial contract? Why or why not?

Which activities were outsourced? Were there high levels of customization?

What were the major uncertainties/risks at the start of the relationship?

Were there any major technological or environmental challenges?

Would you be able to switch this contract easily to a different supplier?

Was there enough in-house contracting expertise?

What were the most important contractual mechanisms at the start of the relationship?

What was the role of those contractual mechanisms?

\section{(3) Risks and MC design over time}

How did the risks change over time?

Have you concluded additional arrangements or changed existing arrangements over time?

Were new controls added, were some controls refined, did some controls disappear?

How did these changes take place: orally, through written communication, or through contractual change?

Did the role of the controls change over time?

How do you perceive the cooperation with your partner over time? What is most needed for good cooperation?

\section{(4) The role of learning in designing MCs}

What was the main source of knowledge that informed the design of the initial contract?

Did you rely on previous experiences?

Did you rely on external parties?

Did you rely on any theoretical simulations or thought experiments?

Did you rely on any other learning processes?

What, if any, lessons were gained during the relationship over time and led to control changes?

Could you give an example of such learning and tell us how it affected the subsequent control choice?

What drove the revision of the contract over time?

What was the role of controls or additional arrangements themselves in creating/integrating new knowledge over time?

\section{References}

Abernethy, M.A., Vagnoni, E., 2004. Power, organization design and managerial behaviour. Account. Organ. Soc. 29 (3), 207-225.

Anderson, S.W., Dekker, H.C., 2005. Management control for market transactions: the relationship between transaction characteristics, incomplete contract design, and subsequent performance. Manage. Sci. 51 (12), 1734-1752.

Anderson, S.W., Dekker, H.C., 2014. The role of management control in transforming firm boundaries and sustaining hybrid organizational forms. Found. Trendsâ® Account. 8 (2), 75-141.

Argote, L., Miron-Spektor, E., 2011. Organizational learning: from experience to knowledge. Organ. Sci. 22 (5), 1123-1137.

Argyres, N.S., Mayer, K.J., 2007. Contract design as a firm capability: an integration of learning and transaction cost perspectives. Acad. Manag. Rev. 32 (4), 1060-1077.

Ariño, A., Reuer, J.J., Mayer, K.J., Jané, J., 2014. Contracts, negotiation, and learning: an examination of termination provisions. J. Manag. Stud. 51 (3), 379-405.

Baiman, S., Rajan, M.V., 2002. Incentive issues in inter-firm relationships. Account. Organ. Soc. 27 (3), 213-238.

Biddle, B.J., 1979. Role Theory: Expectations, Identities, and Behaviors. Academic Press, New York.

Bingham, C.B., Davis, J.P., 2012. Learning sequences: their existence, effect, and evolution. Acad. Manag. J. 55 (3), 611-641.

Caglio, A., Ditillo, A., 2008. A review and discussion of management control in inter-firm relationships: achievements and future directions. Account. Organ. Soc. 33 (7-8),
865-898.

Cook, T.D., Campbell, D.T., 1979. Reproduced in part. The Design and Conduct of True Experiments and Quasi-experiments in Field Settings. Research in Organizations: Issues and Controversies. Goodyear Publishing Company, Santa Monica, California. Costello, A.M., 2013. Mitigating incentive conflicts in inter-firm relationships: evidence from long-term supply contracts. J. Account. Econ. 56 (1), 19-39.

Crossan, M.M., Lane, H.W., White, R.E., 1999. An organizational learning framework: from intuition to institution. Acad. Manag. Rev. 24 (3), 522-537.

Dekker, H.C., 2004. Control of inter-organizational relationships: evidence on appropriation concerns and coordination requirements. Account. Organ. Soc. 29 (1), 27-49.

Dekker, H.C., 2008. Partner selection and governance design in interfirm relationships. Account. Organ. Soc. 33 (7-8), 915-941.

Dekker, H.C., 2016. On the boundaries between intrafirm and interfirm management accounting research. Manag. Account. Res. 31, 86-99.

Dekker, H.C., Van den Abbeele, A., 2010. Organizational learning and inter-firm control: the effects of partner search and prior exchange experiences. Organ. Sci. 21 (6), 1233-1250.

Dekker, H.C., Sakaguchi, J., Kawai, T., 2013. Beyond the contract: managing risk in supply chain relations. Manag. Account. Res. 24 (2), 122-139.

Ding, R., Dekker, H.C., Groot, T., 2013. Risk, partner selection and contractual control in interfirm relationships. Manag. Account. Res. 24 (2), 140-155.

Dunk, A.S., 2011. Product innovation, budgetary control, and the financial performance of firms. Br. Account. Rev. 43 (2), 102-111.

Duplat, V., Lumineau, F., 2015. Third parties and contract design: the case of contracts for 
technology transfer. Manage. Decis. Econ. 37 (6), 424-444.

Edmondson, A.C., 2002. The local and variegated nature of learning in organizations: a group-level perspective. Organ. Sci. 13 (2), 128-146.

Eisenhardt, K.M., 1989. Building theories from case study research. Academic Management Review 14 (4), 532-550.

Faems, D., Janssens, M., Madhok, A., Van Looy, B., 2008. Toward an integrative perspective on alliance governance: connecting contract design, trust dynamics, and contract application. Acad. Manag. J. 51 (6), 1053-1078.

Floyd, S.W., Lane, P.J., 2000. Strategizing throughout the organization: managing role conflict in strategic renewal. Acad. Manag. Rev. 25 (1), 154-177.

Free, C., 2007. Supply-chain accounting practices in the UK retail sector: enabling or coercing collaboration? Contemp. Account. Res. 24 (3), 897-933.

Gulati, R., Singh, H., 1998. The architecture of cooperation: managing coordination costs and appropriation concerns in strategic alliances. Adm. Sci. Q. 43, 781-814.

Hamel, G., 1991. Competition for competence and inter-partner learning within international strategic alliances. Strateg. Manage. J. 12 (4), 83-103.

Harvey, N., Fischer, I., 1997. Taking advice: accepting help, improving judgment, and sharing responsibility. Organ. Behav. Hum. Decis. Process. 70, 117-133.

Heath, C., Gonzalez, R., 1995. Interaction with others increases decision confidence but not decision quality: evidence against information collection views of interactive decision making. Organ. Behav. Hum. Decis. Process. 61 (3), 305-326.

Hoetker, G., Mellewigt, T., 2009. Choice and performance of governance mechanisms: matching alliance governance to asset type. Strateg. Manage. J. 30 (10), 1025-1044.

Huber, G.P., 1991. Organizational learning: the contributing processes and the literatures. Organ. Sci. 2 (1), 88-113.

Janowicz-Panjaitan, M., Krishnan, R., 2009. Measures for dealing with competence and integrity violations of interorganizational trust at the corporate and operating levels of organizational hierarchy. J. Manag. Stud. 46 (2), 245-268.

Janowicz-Panjaitan, M., Noorderhaven, N.G., 2009. Trust, calculation, and interorganizational learning of tacit knowledge: an organizational roles perspective. Organ. Stud. 30 (10), 1021-1044.

Kamminga, P.E., Van der Meer-Kooistra, J., 2007. Management control patterns in joint venture relationships: a model and an exploratory study. Account. Organ. Soc. 32 (1-2), 135-158.

Kamoche, K., Cunha, M.P., 2001. Minimal structures: from jazz improvisation to product innovation. Organ. Stud. 22 (5), 733-764.

Kloot, L., 1997. Organizational learning and management control systems: responding to environmental change. Manag. Account. Res. 8 (1), 47-73.

Knechel, W.R., Leiby, J., 2016. If you want my advice: status motives and audit consultations about accounting estimates. J. Account. Res. 54 (5), 1331-1363.

Langfield-Smith, K., Smith, D., 2003. Management control and trust in outsourcing relationships. Manag. Account. Res. 14 (3), 281-307.

Leonard-Barton, D., 1990. A dual methodology for case studies: synergistic use of a longitudinal single site with replicated multiple sites. Organ. Sci. 1 (3), 248-266.

Lumineau, F., Fréchet, M., Puthod, D., 2011. An organizational learning perspective on the contracting process. Strateg. Organ. 9 (1), 8-32.

Mayer, K.J., Argyres, N.S., 2004. Learning to contract: evidence from the personal computer industry. Organ. Sci. 15 (4), 394-410.

Phua, Y.S., Abernethy, M.A., Lillis, A.M., 2011. Controls as exit barriers in multiperiod outsourcing arrangements. Account. Rev. 86 (5), 1795-1834.

Ricoeur, P., 1984. Time and Narrative. University of Chicago Press, Chicago, IL.

Ryall, M.D., Sampson, R.C., 2009. Formal contracts in the presence of relational enforcement mechanisms: evidence from technology development projects. Manage. Sci. 55 (6), 906-925.

Tomkins, C., 2001. Interdependencies, trust and information in relationships, alliances and networks. Account. Organ. Soc. 26 (2), 161-191.

Van der Meer-Kooistra, J., Scapens, R., 2015. Governing product co-development projects: the role of minimal structures. Manage. Account. Res. 28, 68-91.

Van der Meer-Kooistra, J., Scapens, R., 2018. The governance of collaborative product development. In: Carlsson-Wall, M., Håkansson, H., Kraus, K., Lind, J., Strömsten, T. (Eds.), Accounting, Innovation and Inter-Organisational Relationships. Routledge, New York, pp. 238-260.

Van der Meer-Kooistra, J., Vosselman, E.J.G., 2000. Management control of inter-firm transactional relationships: the case of industrial renovation and maintenance. Account. Organ. Soc. 25 (1), 51-77.

Vanneste, B.S., Puranam, P., 2010. Repeated interactions and contractual detail: identifying the learning effect. Organ. Sci. 21 (1), 186-201.

Vélez, M., Sanchez, J., Alvarez-Dardet, C., 2008. Management control systems as interorganizational trust builders in evolving relationships: evidence from a longitudinal case study. Account. Organ. Soc. 33 (7-8), 968-994.

Vosselman, E., Van der Meer-Kooistra, J., 2009. Accounting for control and trust building in interfirm transactional relationships. Account. Organ. Soc. 34 (2), 267-283.

Williamson, O.E., 1985. Economic Institutions of Capitalism. The Free Press, New York.

Williamson, O.E., 1996. The Mechanisms of Governance. Oxford University Press, New York.

Zollo, M., Winter, S.G., 2002. Deliberate learning and the evolution of dynamic capabilities. Organ. Sci. 13 (3), 339-351. 